\title{
Relationship Of Discipline And Leadership With Employee Performance (Case Study PT. Samsung Electronics Indonesia Surabaya Region)
}

\author{
Anggiezka Natalita Angelica dan Hermien Tridayanti \\ Program Studi Manajemen, Fakultas Ekonomi Dan Bisnis \\ Universitas Narotama Surabaya \\ Email Author: hermin.tridayanti@narotama.ac.id
}

\begin{abstract}
Discipline and leadership are the two main factors for companies to improve employee performance. Because without discipline and leadership it will produce unsatisfactory results. This study aims to determine and analyze the significant positive relationship between the discipline and leadership variables with the performance of employees at PT. Samsung Electronics Indonesia Surabaya Region. Data collection was carried out by distributing questionnaires to 50 employees of PT. Samsung at WTC (World Trade Center) Surabaya and interviewed employees directly. The research method uses the Rank Spearman correlation. The result of this research is that discipline and leadership have a positive and significant relationship with employee performance. Companies must pay attention to the discipline and leadership that the company has and improve it to improve the quality of employee performance for the better.
\end{abstract}

\section{Keyword:}

Discipline, Leadership, Employee Performance

\section{Pendahuluan \\ 1.1.Latar Belakang}

Setiap perusahaan pasti mempunyai visi dan misi guna memajukan perusahaan mereka, karena dengan adanya visi dan misi maka perusahaan mempunyai sesuatu untuk dituju dan digunakan sebagai landasan bagi perusahaan. Salah satu modal terbesar yang dimiliki oleh perusahaan adalah sumber daya manusia, karyawan yang dimiliki oleh perusahaan adalah penentu bagi perusahaan dalam meraih tujuan. Karyawan harus benarbenar mengetahui tujuan perusahaan agar mereka bisa membantu perusahaan. Kinerja karyawan yang baik adalah tujuan setiap perusahaan karena bagaimanapun kinerja karyawan yang baik sangat dibutuhkan oleh perusahaan demi kelancaran perusahaan dalam mencapai tujuan.

Banyak faktor-faktor yang dapat mempengaruhi kinerja karyawan, menurut Timple dalam Mangkunegara (2005:14), faktor-faktor yang dapat mempengaruhi kinerja terdiri dari 2 faktor yaitu, faktor internal dan faktor eksternal. Faktor internal, adalah faktor yang dihubungkan dengan sifat-sifat seseorang salah satunya adalah disiplin kerja. Faktor eksternal, adalah faktor-faktor yang memengaruhi kinerja seseorang yang berasal dari lingkungan, contoh yang dapat diambil adalah kepemimpinan.

PT. Samsung Electronics Indonesia area Surabaya adalah salah satu perusahaan dalam bidang elektronik, PT. Samsung mempunyai banyak cabang perusahaan dan karyawan di seluruh Indonesia. PT. Samsung mempunyai karyawan yang bergerak di bidang promotor (Experience Consultant) di Mall WTC (World Trade Center) Surabaya.

Hasil dari wawancara kepada beberapa promotor Samsung yang bekerja di WTC adalah terdapat fenomena yang terjadi yaitu pada beberapa bulan terakhir terdapat penurunan kinerja karyawan dan beberapa kayawan yang berhenti dari pekerjaan. Setelah dilakukan wawancara dari beberapa karyawan, dari beberapa pernyataan karyawan-karyawan tersebut bisa disimpulkan bahwa penyebab-penyebab penurunan kinerja karyawan tersebut dikarenakan oleh kepimimpinan yang kurang tepat dan kedisiplinan kerja karena tugas yang terlalu banyak menyebabkan karyawan tidak bersemangat untuk bekerja dan pada akhirnya mengakibatkan penurunan kinerja.

Maka dari itu, peneliti sangat tertarik untuk meneliti tentang fenomena ini karena hubungan kedisiplinan dan kepemimpinan sebenarnya sangat penting bagi kinerja karyawan. Dan sekiranya, peneliti bisa membantu perusahaan dalam memaksimalkan kinerja karyawan dan membantu mengungkap denomena yang sedang terjadi di dalam perusahaan. Hal ini dikarenakan keduanya sangat dekat dengan karyawan. Tanpa kedisiplinan, kinerja karyawan pasti akan menurun karena ketiadaan kedisiplinan akan meruntuhkan peraturan perusahaan dan tanpa peraturan maka karyawan tidak akan bisa mencapai tujuan perusahaan dengan baik. 
Dan juga tanpa kepemimpinan, kinerja karyawan juga dapat menurun dengan pesat. Kepemimpinan bagi karyawan mempunyai peranan penting karena pemimpin bagi karyawan adalah panutan. Jadi jika kepemimpinan tidak dijalanakan dengan sempurna, maka kinerja karyawan pun juga tidak akan bisa berjalan dengan sempurna. Karena bagaimanpun, kepemimpinan seperti penegak hukum atau aturan bagi para karyawan. Dan pemimpinlah yang dapat mengatur dan memotivasi karyawan agar terus dapat meningkatkan kinerjanya.

\subsection{Rumusan Masalah}

Berdasarkan pada uraian di atas dapat dirumuskan masalah sebagai berikut

1. Apakah terdapat hubungan yang signifikan antara variabel kepimimpinan dengan kinerja karyawan di PT Samsung Electronics Indonesia Wilayah Surabaya?

2. Apakah terdapat hubungan yang signifikan antara variabel kedisiplinan dengan kinerja karyawan di PT. Samsung Electronics Indonesia Wilayah Surabaya?

\section{Tinjauan Pustaka}

\subsection{Penelitian Terdahulu}

Tinjauan penelitian terdahulu dapat digunakan sebagai referensi untuk melakukan penelitian lanjutan. Dalam penelitian Tumilaar (2015) yang berjudul Pengaruh Disiplin, Gaya Kepemimpinan, dan Motivasi terhadap Kinerja Karyawan pada BPJS Ketenagakerjaan SULUT. Tujuan dari penelitian ini adalah untuk menguji dan menganalisis pengaruh disiplin, gaya kepemimpinan dan motivasi terhadap kinerja karyawan pada BPJS ketenagakerjaan SULUT. Terdapat perbedaan peneliti Brigita dengan penelitian peneliti, dimana Brigita menggunakan metode analisis regresi linier berganda sedangkan peneliti menggunakan metode korelasi. Dan di penelitian Brigita menggunakan variabel bebasnya gaya kepemimpinan dan motivasi sedangkan peneliti variabel bebasnya adalah kedisiplinan dan kepemimpinan. Persamaan yang terdapat hanyalah penelti sama-sama membahas tentang kedisiplinan dan kepemimpinan terhadap kinerja karyawan.

\subsection{Kedisiplinan}

Kedisiplinan adalah fungsi operatif keenam dari Manajemen Sumber Daya Manusia. Kedisiplinan adalah fungsi operatif dari MSDM yang paling penting, karena semakin baik disiplin karyawan maka akan semakin tinggi juga prestasi kerja yang dapat dicapai oleh seseorang. Tanpa disiplin karyawan yang baik maka dapat membuat sulit organisasi perusahaan dalam mendapatkan hasil yang optimal Hasibuan (2013:193). Disiplin sangat penting dan menjadi pilar bagi perusahaan untuk mencapai tujuan perusahaan. Disiplin yang baik akan mencerminkan seberapa besar tanggung jawab seseorang. Setiap perusahaan pasti mempunyai peraturanperaturan tersendiri agar tidak terjadi kekacauan di dalamnya dan juga agar perusahaan bisa mencapai tujuantujuannya.

Karena jika karyawan di dalam perusahaan tidak taat pada peraturan yang ada maka kinerja karyawan tersebut juga pasti akan menurun dan mereka tidak dapat mencapai tujuan perusahaan. Hukuman atau sanksi juga sangat diperlukan untuk membantu karyawan agar dapat melakukan kedisiplinan. Karena dengan adanya hukuman atau sanksi, maka akan ada efek jera bagi individu dan tidak mengulangi kesalahan yang sama.

\subsection{Kepemimpinan}

Kepemimpinan adalah suatu cara seorang pemimpin dalam mempengaruhi perilaku bawahan agar mau bekerja sama dan bekerja secara produktif agar dapat mencapai tujuan organisasi. Hasibuan (2001). Kepemimpinan sangat dibutuhkan dalam perusahaan agar kinerja karyawan membaik. Bisa dikatakan bahwa pemimpin adalah pilar dan acuan bagi karyawan untuk membuat kinerja yang baik. Pemimpin juga bisa dijadikan contoh atau teladan bagi para karyawan. Jadi, apapun yang diperbuat oleh pemimpin juga akan dicontoh dan dilakukan oleh para karyawannya. Kepemimpinan yang tidak teratur dan diorganisir dengan baik maka akan menyebabkan kinerja karyawan menjadi buruk dan menurun.

Rivai dan Mulyadi (2010) menyatakan bahwa kepemimpinan pada hakikatnya adalah :

1) Proses mempengaruhi atau memberi contoh dari pemimpin pada bawahannya dalam upaya untuk mencapai tujuan perusahaan;

2) Seni mempengaruhi dan juga mengarahkan orang lain dengan cara kepatuhan, kepercayaan, kehormatan, dan juga kerja sama yang bersemangat untuk mencapai tujuan bersama;

3) Kemampuan dalam mempengaruhi, memberi inspirasi dan mengarahkan tindakan individu atau pun kelompok dalam mencapai tujuan yang diharapkan;

4) Kemampuan dalam mempengaruhi suatu kelompok dalam mencapai tujuan. Sumber pengaruh bisa didapatkan secara formal dan tidak formal. Pengaruh formal di dapat jika seorang pemimpin memiliki posisi manajerial di sebuah organisasi. Sementara sumber pengaruh tidak formal bisa di dapat struktur organisasi formal. Seorang pemimpin dapat muncul dari suatu organisasi atau pun karena 
ditunjuk secara formal. Dengan demikian, pengaruh pemimpin sangat ditentukan dari statusnya, yaitu sebagai pimpinan formal atau pimpinan informal.

\subsection{Kinerja Karyawan}

Menurut Rivai (2010), kinerja adalah perilaku nyata yang dapat ditampilkan setiap orang sebagai prestasi kerja yang dapat dihasilkan oleh karyawan sesuai dengan perannya dalam perusahaan. Menurut Mangkunegara (2010) kinerja karyawan adalah hasil kerja secara kualitas dan kuantitas yang dapat dicapai oleh seorang karyawan dalam melaksanakan tugasnya sesuai dengan tanggung jawab yang sudah diberikan kepadanya.

Dari beberapa definisi tersebut bisa disimpulkan bahwa kinerja adalah hasil atau prestasi kerja yang dapat dicapai oleh karyawan saat atau dalam melaksanakan tugas dan tanggung jawab yang diberikan kepada karyawan tersebut. Dalam pembahasan mengenai kinerja maka tidak akan terlepas dari berbagai macam faktorfaktor yang mempengaruhinya :

1. Faktor Kemampuan (ability)

Secara psikologis kemampuan (ability) karyawan terdiri dari kemampuan potensi ( $I Q$ ) dan kemampuan reality (knowledge dan skill). Yang artinya adalah pegawai yang memiliki IQ diatas rata-rata ( 110-120) dengan pendidikan yang memadai untuk jabatannya dan juga terampil saat mengerjakan pekerjaan yang diberikan, oleh karena itu mereka akan lebih mudah mencapai kinerja yang memang diharapkan. Oleh karena itu pegawai perlu ditempatkan pada pekerjaan yang memang sesuai dengan keahliannya.

2. Faktor Motivasi (motivation)

Motivasi dapat terbentuk dari sikap (attitude) seorang karyawan dalam menghadapi beberapa situasi (situation) kerja. Motivasi merupakan kondisi yang dapat menggerakkan diri karyawan yang terarah dalam mencapai tujuan kerja.

3. Faktor Strategi (strategic)

Strategi adalah suatu bentuk sasaran dari kinerja agar dapat mengetahui dan juga mengukur sejauh mana keberhasilan karyawan dalam melaksanakan dan mengerjakan pekerjaannya dengan susunan strategi yang sudah dimilikinya.

\subsection{Hipotesis}

Berdasarkan teori di atas, maka bisa dikatakan penelitian ini mempunyai hipotesis. Hipotesis adalah dugaan sementara di dalam suatu peneleitian. Karena hipotesis bersifat masih dugaan sementara, maka perlu diuji kebenarannya melalui uji hipotesis. Berdasarkan pada teori dan landasan pemikiran di atas, maka rumusan hipotesis penelitian ini adalah :

1. Hipotesis I :

$\mathrm{H}_{0}$ : Tidak terdapat hubungan yang signifikan antara Kedisiplinan dengan Kinerja Karyawan

$\mathrm{H}_{1}$ : Terdapat hubungan yang positif signfikan antara Kedisiplinan dengan Kinerja Karyawan

2. $\quad \mathrm{H}_{0}$ : Tidak terdapat hubungan yang signifikan antara Kepemimpinan dengan Kinerja Karyawan

$\mathrm{H}_{1}$ : Terdapat hubungan yang positif signifikan antara Kepemimpinan dengan Kinerja Karyawan

\section{Metode Penelitian}

\subsection{Gambaran Umum Objek Penelitian}

Pada tahun 1938, Lee Byung-Chull (1910-1987) dari keluarga pemilik tanah besar di daerah Uiryeong datang ke kota Daegu dekatnya dan dari situ ia mendirikan Samsung Sanghoe, sebuah perusahaan perdagangan kecil dengan empat puluh karyawan yang berlokasi di Su-dong (yang sekarang dikenal dengan Ingyo-dong).

Menurut pendiri Samsung Group, arti dari kata hanja Korea Samsung, adalah "tristar" atau "tiga bintang". Kata "tiga" adalah merupakan sesuatu yang "besar, banyak dan kuat". Dari 1938 sejak saat berdirinya Samsung, Perusahaan menjadi makmur, kemudian Lee memindahkan kantor pusatnya ke Seoul pada tahun 1947. Pada saat Perang Korea pecah, ia terpaksa meninggalkan Seoul dan memulai penyulingan gula di Busan yang bernama Cheil Jedang.

Di tahun 1987, pendiri samsung (Lee) meninggal. Kemudian Samsung Group terpecah menjadi empat kelompok; Samsung Group, Shinsegae Group, CJ Group and Hansol Group. Sejak tahun 1990-an Samsung semakin menglobal kegiatannya di dalam bidang elektronik, khususnya ponsel dan semikonduktor. Dari sini Samsung mulai mencoba mendirikan berbagai anak perusahaan dan bisnis afiliasi, kebanyakan dari mereka bersatu di bawah merek Samsung

Pada tahun 2013, Samsung mulai konstruksi pada bangunan terbesar pabrik ponsel dunia di provinsi Thai Nguyen dari Vietnam. Samsung telah mampu mencapai pangsa pasar terbesar hampir 31\% di segmen smartphone global, pada tahun 2013. Dan dari masa dulu sampai sekarang, Samsung menjadi brand elektronik yang terkenal dan menguasai pangsa pasar. 


\subsection{Metode}

Pada penelitian ini, peneliti menggunakan metode kuantitatif yaitu dengan menggunakan metode survey. Menurut Singarimbun, Effendi (1989) metode survey adalah metode yang mengambil suatu contoh data dari suatu populasi dan menggunakan kuisioner untuk alat pengumpulan data pokok. Unit analisis dalam penelitian ini adalah pegawai PT. Samsung Electronics Indonesia bagian Surabaya dalam bidang Promotor cabang WTC (World Trade Center) Surabaya.

Di penelitian ini akan meneliti pegawai Samsung bagian Promotor di bagian WTC Surabaya yang total berjumlah 50 pegawai. Teknik pengambilan sampel akan menggunakan metode sensus. Semua pegawai di PT. Samsung Electronics Surabaya yang ditempatkan di WTC akan dijadikan sampel sejumlah 50 pegawai

Penelitian ini menggunakan alat ukur kuisioner yang akan disebar dan dijawab oleh 50 karyawan PT. Samsung Electronics yang terdapat di WTC Surabaya. Skala pengukuran di dalam penelitian ini diukur dengan skala likert ( likert scalling) dan data berjenis ordinal. Teknik penilaian adalah satu dimensi dari konsep yang diterjemahkan ke dalam serangkaian pernyataan, kemudian responden akan diminta untuk menjawab pernyataan-pernyataan tersebut. Setiap alternatif jawaban kuesioner untuk seluruh indikator akan diberi skor penilaian dengan ketentuan sebagai berikut :

Nilai 5, jika jawaban Sangat Setuju

Nilai 4, jika jawaban adalah Setuju,

Nilai 3, jika jawaban adalah Kurang Setuju,

Nilai 2, jika jawaban adalah Tidak Setuju,

Nilai 1, jika jawaban adalah Sangat Tidak Setuju

\subsection{Desain Instrumen Penelitian}

Tabel 1. Desain dan Instrumen Penelitian

\begin{tabular}{lll}
\hline Variabel Penelitian & Indikator & Skala \\
\hline Kepemimpinan (Rivai dan & 1. Fungsi Instruksi & Likert \\
Mulyadi, 2010:34) & 2. Fungsi Konsultasi & Likert \\
& 3. Fungsi Partisipasi & Likert \\
& 4. Fungsi Delegasi & Likert \\
5. Fungsi Pengendalian & Likert \\
Kedisiplinan (Hasibuan, & 1. Tujuan dan Kemampuan & Likert \\
2013:194) & 2. Teladan Pimpinan & Likert \\
& 3. Balas Jasa & Likert \\
& 4. Keadilan & Likert \\
& 5. Waskat & Likert \\
& 6. Sanksi Hukuman & Likert \\
& 7. Ketegasan & Likert \\
8. Hubungan Kemanusiaan & Likert \\
1. Kualitas & Likert \\
2. Kuantitas & Likert \\
& 3. Ketepatan Waktu & Likert \\
& 4. Tanggung Jawab & Likert \\
\hline
\end{tabular}

\section{Hasil Penelitian \\ 4.1.Validitas}

Hasil uji validitas dapat dilihat pada tabel 2 
Tabel 2. Validasi

\begin{tabular}{ccccc}
\hline Variabel & Indikator & $\begin{array}{c}\text { Koefisien } \\
\text { Korelasi } \\
\left(r_{\text {hitung }}\right.\end{array}$ & $\begin{array}{c}\text { Nilai Kritis } \\
\left(r_{\text {tabel }}\right)\end{array}$ & Keterangan \\
\hline \multirow{3}{*}{$\mathrm{X} 1$} & $\mathrm{X} 1.1$ & .412 & 0,2787 & Valid \\
& $\mathrm{X} 1.3$ & .488 & 0,2787 & Valid \\
& $\mathrm{X} 1.4$ & .576 & 0,2787 & Valid \\
& $\mathrm{X} 1.5$ & .664 & 0,2787 & Valid \\
& $\mathrm{X} 1.6$ & .702 & 0,2787 & Valid \\
$\mathrm{X} 1.7$ & .496 & 0,2787 & Valid \\
$\mathrm{X} 2$ & $\mathrm{X} 1.8$ & .384 & 0,2787 & Valid \\
& $\mathrm{X} 2.1$ & .398 & 0,2787 & Valid \\
& $\mathrm{X} 2.2$ & .595 & 0,2787 & Valid \\
& $\mathrm{X} 2.3$ & .649 & 0,2787 & Valid \\
& $\mathrm{X} 2.4$ & .666 & 0,2787 & Valid \\
$\mathrm{Y}$ & $\mathrm{Y} .1$ & .306 & 0,2787 & Valid \\
& $\mathrm{Y} .2$ & .555 & 0,2787 & Valid \\
& $\mathrm{Y} .3$ & .544 & 0,2787 & Valid \\
& $\mathrm{Y} .4$ & .570 & 0,2787 & Valid \\
\hline
\end{tabular}

Pada tabel di atas bisa dilihat bahwa data pernyataan pada kuisioner dinyatakan valid karena nilai koefisien korelasi (r hitung) lebih besar dari nilai kritis ( $\mathrm{r}$ tabel). Oleh karena itu bisa dikatakan bahwa alat ukur untuk mengukur penelitian ini dapat dipenuhi dan valid. Jadi, kuisioner ini bisa diajukan kepada responden untuk mengukur apa yang akan diukur di dalam penelitian ini. Dan kuisioner ini bisa memberikan data yang dibutuhkan oleh penelitian ini.

\subsection{Reliabilitas}

Reliabilitas adalah sesuatu instrumen yang dapat dipercaya untuk digunakan sebagai alat pengumpul data karena instrumen tersebut sudah baik dan terpercaya (Arikunto, 2010).

Reliability Statistics

Cronbach's Alpha
.874

Menurut Sugiyono (2012) suatu instrumen dapat dinyatakan reliabel jika koefisien reliabilitas minimal 0.60. Maka bisa dikatakan jika cronbach alpha di bawah 0.60 maka data dinyatakan tidak reliabel dan sebaliknya jika cronbach alpha di ats 0.60 maka data dinyatakan reliabel. Dan bisa dilihat bahwa di tabel tersebut, data penelitian ini mempunyai cronbach alpha .874 dan berada di atas 0.60 , maka data penelitian ini dapat dinyatakan reliabel dan dapat dipercaya.

\subsection{Hasil Korelasi} Spearman :

Korelasi yang digunakan adalah korelasi Rank Spearman. Berikut ini adalah hasil dari uji korelasi Rank 
Tabel 4. Hasil Korelasi

Correlations

\begin{tabular}{|c|c|c|c|c|c|}
\hline & & & $\mathrm{X} 1$ & X2 & Y \\
\hline \multirow[t]{9}{*}{ Spearman's rho } & $\mathrm{X} 1$ & Correlation Coefficient & 1.000 & $.744^{* *}$ & $.757^{* *}$ \\
\hline & & Sig. (2-tailed) & & .000 & .000 \\
\hline & & $\mathrm{N}$ & 50 & 50 & 50 \\
\hline & $\mathrm{X} 2$ & Correlation Coefficient & $.744^{* *}$ & 1.000 & $.507^{* *}$ \\
\hline & & Sig. (2-tailed) & .000 & . & .000 \\
\hline & & $\mathrm{N}$ & 50 & 50 & 50 \\
\hline & Y & Correlation Coefficient & $.757^{* *}$ & $.507^{* *}$ & 1.000 \\
\hline & & Sig. (2-tailed) & .000 & .000 & \\
\hline & & $\mathrm{N}$ & 50 & 50 & 50 \\
\hline
\end{tabular}

1. Hubungan Kedisiplinan (X1) dengan Kepemimpinan (X2) bisa dikatakan kuat dan signifikan karena nilai koefisien korelasi mempunyai hasil 0,744 dengan tingkat signifikansi 0,000.

2. Hubungan Kedisiplinan (X1) dengan Kinerja Karyawan (Y) bisa dikatakan kuat dan signifikan karena nilai koefisien korelasi mempunyai hasil 0,757 dengan tingkat signifikansi 0,000.

3. Hubungan Kepemimpinan (X2) dengan Kinerja Karyawan (Y) bisa dikatakan sedang dan signifikan karena nilai koefisien korelasi mempunyai hasil 0,507 dengan tingkat signifikansi 0,000.

\subsection{Pengujian Hipotesis}

1. Hipotesis I:

Tingkat signifikansi yang dimiliki antara variabel Kedisiplinan (X1) dengan variabel Kinerja Karyawan (Y) adalah 0,000 dan 0,000 < 0,05 yang berarti signifikansi sudah terpenuhi dan dapat dinyatakan bahwa $\mathrm{H}_{0}$ ditolak. Dan bisa dipastikan bahwa terdapat korelasi yang signifikan antara variabel Kedisiplinan (X1) dengan variabel Kinerja Karyawan (Y).

2. Hipotesis II:

Tingkat signifikansi yang dimiliki antara variabel Kepemimpinan (X2) dengan variabel Kinerja Karyawan (Y) adalah 0,000 dan 0,000 $<0,05$ yang berarti signifikansi sudah terpenuhi dan dapat dinyatakan bahwa $\mathrm{H}_{0}$ ditolak. Dan bisa dipastikan bahwa terdapat korelasi yang signifikan antara variabel Kepemimpinan (X2) dengan variabel Kinerja Karyawan (Y).

\section{Pembahasan Hasil Penelitian}

Berdasarkan dari hasil penelitian dan interpretasi nilai $\mathrm{r}$ yang sudah dilakukan bisa diketahui bahwa variabel Kedisplinan (X1) dengan variabel Kinerja Karyawan (Y) mempunyai hasil yang paling besar yaitu 0,757 yang jika diartikan menurut tabel interpretasi nilai $\mathrm{r}$ berada pada range 0,60 - 0,799 mengindikasikan tingkat hubungan kuat dan mempunyai tingkat signifikansi 0,000 , yang artinya $0,000<0,05$ maka tingkat signifikansi sudah terpenuhi. Maka bisa dikatakan bahwa Kedisiplinan (X1) dengan Kinerja Karyawan (Y) mempunyai hubungan yang kuat dan signifikan.

Dan hasil data ini didukumg oleh keadaaan yang sebenarnya di dalam perusahaan memang adanya hubungan yang kuat antara kedisiplinan dengan kinerja karyawan karena karyawan mempunyai masalah dengan kedisiplinan yang memang sudah diduga dari awal terjadinya masalah karyawan dikarenakan kedisiplinan yang tidak terorganisir dengan baik.

Hubungan yang mempunyai hasil yang paling rendah daripada hubungan yang lain adalah variabel Kepemimpinan (X2) dengan variabel Kinerja Karyawan (Y) yang mempunyai hasil 0,507 yang diartikan menurut tabel interpretasi $\mathrm{r}$ berada pada range 0,40-0,599 mengindikasikan tingkat hubungan sedang dengan nilai signifikansi 0,000 yang berarti tingkat signifikansi telah terpenuhi. Maka bisa dikatakan variabel Kedisiplinan (X2) dengan variabel Kinerja Karyawan (Y) mempunyai hubungan yang sedang dan signifikan walaupun mempunyai nilai korelasi yang paling rendah dibandingkan dengan hubungan yang lainnya. Walaupun korelasi Kepemimpinan (X2) dan Kinerja Karyawan (Y) mempunyai hubungan yang sedang dan tidak sekuat korelasi yang lainnya, akan tetapi keduanya tetap mempunyai hubungan yang dapat mempengaruhi satu sama lain.

Hasil ini didukung oleh keadaan karyawan yang sebenarnya yang memang diduga mempunyai masalah dengan kepemimpinan. Dan memang terbukti jika antara kepemimpinan dengan kinerja karyawan mempunyai hubungan yang kuat dan bisa menyebabkan masalah bagi para karyawan jika tidak dilakukan dengan benar dan baik. 


\section{Penutup}

\subsection{Kesimpulan} berikut:

Berdasarkan hasil dari hipotesis dan pembahasan penelitian, maka bisa ditarik kesimpulan sebagai

1. Variabel kedisiplinan dan kinerja karyawan mempunyai hasil korelasi sebesar 0,757 dengan tingkat signifikansi 0,000 yang mengindikasikan bahwa hubungan yang dimiliki sangat kuat dan signifikan. Maka bisa dikatakan bahwa kedisiplinan mempunyai kontribusi yang besar terhadap kinerja karyawan dan sangat berhubungan satu sama lain. Maka dari itu, penting bagi perusahaan untuk meningkatkan kedisiplinannya guna meningkatkan kinerja karyawan.

2. Variabel kepemimpinan dan kinerja karyawan mempunyai hasil korelasi sebesar 0,507 dengan tingkat signifikansi 0,000 yang mengindikasikan bahwa hubungan yang dimiliki sedang dan signifikan. Walaupun, hubungan kepemimpinan dan kinerja karyawan tidak sebesar hubungan yang dimiliki kedisiplinan dan kinerja karyawan, akan tetapi kepemimpinan tetap mempunyai peranan yang penting bagi karyawan. Di dalam hasil penelitian kepemimpinan menunjukkan hasil hubungan yang sedang terhadap kinerja karyawan yang artinya adalah kepemimpinan tetap mempunyai kontribusi yang cukup bagi kinerja karyawan. Dan hendaknya perusahaan bisa meningkatkan kepemimpinan guna meningkatkan kinerja karyawan.

\subsection{Saran}

Dari kesimpulan di atas, bisa dilihat bahwa kedisiplinan dan kepemimpinan mempunyai hubungan yang cukup kuat bagi kinerja karyawan di PT. Samsung Electronics Indonesia wilayah Surabaya (bagian WTC Surabaya). Dan hal ini harus diperhatikan oleh perusahaan jika perusahaan mau mempunyai kualitas kinerja karyawan yang tinggi dan bagus. Karena, kinerja karyawan yang berkualitas bisa menjadi penentu sukses atau tidaknya suatu perusahaan, jadi hendaknya perusahaan memperhatikan hal-hal yang berhubungan kuat dengan kinerja karyawan.

Saran yang bisa diberikan oleh penulis bagi perusahaan berdasarkan hasil penelitian adalah perusahaan bisa mengobservasi ulang peraturan-peraturan yang terdapat di dalam perusahaan dan melihat apakah ada peraturan yang memang tidak sesuai dengan kemampuan para karyawan, karena penyebab kurangnya kedisiplinan salah satunya adalah karyawan sebenarnya tidak mampu mengikuti peraturan yang ada. Dan memang hendaknya peraturan-peraturan yang terdapat di dalam perusahaan disesuaikan dengan kemampuan karyawan itu sendiri. Jika memang ada peraturan yang memang tidak sesuai dengan kemampuan karyawan, maka perusahaan hendaknya mengganti peraturan tersebut dengan peraturan yang baru yang sesuai dengan kemampuan karyawan dan dapat diikuti oleh semua karyawan.

Saran selanjutnya, masih mengenai kurangnya kedisiplinan perusahaan bisa mengambil tindakan dengan mengadakan pelatihan, penyuluhan dan seminar-seminar untuk membahas pentingnya kedisiplinan dan membahas bagaimana caranya meningkatkan kedisiplinan. Dengan adanya pelatihan ini maka diharapkan karyawan dapat mengerti bagaimana caranya meningkatkan kedisiplinan mereka untuk perusahaan dan juga untuk melatih kedisiplinan mereka sendiri. Hendaknya karyawan dapat mengetahui kiat-kiat yang dapat diambil untuk lebih disiplin.

Perusahaan juga hendaknya lebih tegas dalam menjalankan hukuman bagi karyawan yang tidak disiplin agar terdapat efek "jera" bagi para karyawan dan tidak mengulangi kesalahan yang sama. Dengan adanya hukuman dan ketegasan yang baik dan teratur maka akan menciptakan lingkungan kerja yang mempunyai disiplin yang baik pula. Dan dengan adanya lingkungan kerja yang disiplin maka akan memberikan karyawan latihan dalam berdisiplin yang baik dan akan memberikan mereka kebiasaan disiplin yang pada akhirnya akan meningkatkan kedisiplinan karyawan di dalam perusahaan.

Selanjutnya untuk saran dalam kepemimpinan, perusahaan bisa mengobservasi lagi kepemimpinan yang terjadi di dalam perusahaan. Dan hendaknya jika memang ada yang tidak sesuai dan tidak baik di dalam kepemimpinan tersebut, pemimpin hendaknya memperbaiki kepemimpinan tersebut. Karena bagaimanapun kepemimpina mempunyai peran yang sangat besar di dalam kinerja karyawan.

Kepemimpinan dan karyawan ini bisa mempunyai hubungan yang lebih erat jika perusahaan bisa memberikan acara-acara yang dapat dikunjungi oleh pemimpin dan karyawan. Hal ini ditujukan agar pemimpin dan karyawan bisa lebih dekat dan mempunyai hubungan yang lebih harmonis agar keduanya mempunyai rasa hormat dan dapat menghargai satu sama lain agar tidak terjadi kesenjangan

\section{Daftar Pustaka}

Abidin, Fudin Zainal. 2013. Pengaruh Disiplin terhadap Kinerja Karyawan pada PT. Rekatama Putra Gegana Bandung. Bandung. Universitas Winaya Mukti.

Hasibuan, H Malayu. 2013. Manajemen Sumber Daya Manusia. Jakarta. PT Bumi Aksara.

Mangkunegara, Anwar Prabu. 2009. Evaluasi Kinerja Sumber Daya Manusia. Bandung. Refika Aditama.

Oktavia, Fenny Dwi. 2014. Pengaruh Kepemimpinan dan Disiplin Kerja terhadap Kinerja Pegawai pada Dinas Pendidikan Kota Bengkulu. Bengkulu. Universitas Bengkulu. 
Pahlevi Cepi, et. Al. 2015. Effects of Leadership, Competency, and Work Discipline on the Application of Total Quality Management and Employees' performance for the Accreditation Status Achievement of Government Hospitals, Jakarta, Indonesia. ISSN 2201-2796. Makassar. Universitas Hasanuddin.

Rivai Veithzal dan Mulyadi Deddy. 2010. Kepemimpinan dan Perilaku Organisasi. Jakarta. Raja Grafindo Persada.

Robbins, Stephen P. 2006. Perilaku Organisasi. Edisi Kesepuluh. Jakarta. PT Gramedia

Romadhon S. 2012. Hubungan gaya kepemimpinan autokratis dengan kinerja karyawan bagian pemasaran PT Puji Surya Indah. Surabaya. Universitas Narotama.

Santoso, Singgih. 2010. Statistik Parametrik Konsep dan Aplikasi dengan SPSS. Jakarta. PT Elex Media Komputindo.

Sugiyono. 2002. Metode Statistika. Bandung. Tarsito.

Sugiyono. 2004. Pengantar Statistika. Jakarta. PT Gramedia Pustaka.

Tumilaar, Brigita Ria. 2015. Pengaruh Disiplin, Gaya Kepemimpinan, dan Motivasi terhadap Kinerja Karyawan pada BPJS Ketenagakerjaan SULUT. ISSN 2303-1174. Manado. Universitas Sam 